\title{
Effect of occupational exposure to benzene on phytohaemagglutinin (PHA) stimulated lymphocytes
} in man

\author{
A YARDLEY-JONES,' DIANA ANDERSON, ${ }^{2}$ P JENKINSON ${ }^{2}$ \\ From the Occupational Health Division,' Shell-Mex House, London, and the British Industrial Biological \\ Research Association, ${ }^{2}$ Carshalton, Surrey SM5 4DS, UK
}

\begin{abstract}
This study was carried out to investigate the effects of potential low level exposure to benzene on phytohaemagglutinin (PHA) stimulated lymphocytes. Sixty six male workers of a refinery population were studied and compared with 33 control workers in the same refinery who were not known to have been exposed to benzene. The responsiveness of the lymphocyte to PHA as a measure of blastogenesis was measured by the incorporation of radio labelled thymidine by the stimulated lymphocytes in vitro. Questionnaires were used to determine various lifestyle factors such as smoking, drinking, and exposure to ionising radiation. The results showed that there was no difference between the exposed group (mean $28928+1524$ SE (decays per minute (DPM)) as compared with the control group (mean $28304+2483$ SE DPM). Furthermore, it was not possible to determine any effects attributable to various social factors. There was, however, a suggestion of a decrease in mitogenic response with age in both exposed and control workers that was consistent with other studies. It has been shown that products of benzene metabolism may affect the mitogenic response of lymphocytes in a similar way to known promoting agents. This study was unable to show these effects, probably as a result of the low exposures encountered by the individuals.
\end{abstract}

It is now well established that repeated exposure to benzene at high concentration is associated with leukaemias and lymphomas in man' and other types of cancers such as Zymbal gland and hepatocellular carcinomas found more often in rodents. ${ }^{2}$ Other blood discrasias have been described in both man and experimental animals and these have included lymphocytopaenia, thrombocytopaenia, and pancytopaenia or aplastic anaemia. ${ }^{3}$ Epidemiological studies have established that chronic exposure to benzene at concentrations of about $100 \mathrm{ppm}$ or greater results in an increase in the incidence of acute myelogenous leukaemia and, possibly, lymphoma in man. ${ }^{4}$ Over the past decade, however, there has been a substantial reduction in the occupational exposure to benzene and regulatory bodies have used both epidemiological and scientific evidence to evaluate the risk to health so that control limits may be set. Nevertheless, the importance with respect to human health of exposure to lower concentrations of benzene (1-10 ppm) is currently the subject of much controversy and has been the subject of many reviews and risk assessments. ${ }^{5}$ Whatever the permitted maximal Accepted 3 August 1987 exposure per working day, accidental spillages, and thus peak transient exposures, will occasionally still occur. Great variability exists in the sensitivity of individuals when exposed to benzene and factors such as age, genotype, immunocompetence, and lifestyle complicate assessment of the probable causes of benzene toxicity. ${ }^{6}$ In addition, the duration of exposure to and dose of benzene makes interpretation of epidemiological studies extremely difficult.

There is also much debate as to the mechanism by which benzene exerts its toxicological effect and in particular its carcinogenicity. Although the bioactivation of benzene is complex, it is now accepted that benzene requires metabolism to exert its toxic effects. Phenol is formed by the oxidation of benzene in the liver by the cytochrome P450 system. The principal secondary metabolites of benzene, hydroquinone, and catechol are also formed in the liver; the former by hydroxylation of phenol and the latter by dehydrogenation of benzene dihydrodiol. ${ }^{7}$ Suppression of cell growth and function in bone marrow and the lymphoid system correlates with the concentration of hydroquinone and catechol that accumulates in bone marrow and lymphoid tissue after exposure to ben- 
zene. ${ }^{8}$ Although the bone marrow possesses a limited capacity to metabolise benzene, it seems insufficient to account for the concentration of its metabolites occurring in this tissue. ${ }^{9}$ Phenol, however, is readily metabolised in bone marrow. ${ }^{10}$ The relative contribution of each of these pathways in the induction of bone marrow toxicity after exposure to benzene, however, remains unclear, but the quinone metabolites of benzene have proved to be toxic to bone marrow and lymphoid cells both in vivo and in vitro. "12 Quinones are formed by the oxidation of hydroquinone or catechol. Hydroquinone itself then oxidises under physiological conditions in vitro to form parabenzoquinone, forming the parasemiquinone intermediate in the reaction. Irons has recently reviewed the current understanding of the disposition and bioactivation of benzene..$^{13}$

Putative hypotheses of the mechanisms of benzene toxicity include free radical formation via superoxide, covalent binding of the semiquinones to DNA, RNA, or other cellular macromolecules or, alternatively, direct alkylation of sulphydryl groups by parabenzoquinone or its orthohydroxy derivative. Studies conducted by Irons et al over the past years have indicated that the latter mechanism figures predominantly in the suppression of cell growth associated with hydroquinone and parabenzoquinone.

Benzene metabolites have been shown to affect both the bone marrow and lymphoid cells of rats, in vivo and in vitro including reduction in cellularity, suppression of lymphocyte function, and sister chromatid exchanges. ${ }^{1214}$ The importance of these alterations with respect to bone marrow damage or leukaemogenesis is not clear; however, potent suppression of cell growth blastogenesis by these compounds suggests that this mechanism is important with respect to bone marrow and lymphoid suppression and aplastic anaemia.

Phenol, hydroquinone, and catechol suppress cell growth in rats in vivo. Neither phenol nor catechol suppress lymphocyte growth or function at concentrations that do not result in cell death. Hydroquinones, however, suppress mitogen induced lymphocyte blas- togenesis at relatively low concentrations, and parabenzoquinone is about twice as potent as hydroquinone. ${ }^{15}$

By using the well established technique of mitogen induced blastogenesis it was decided, as part of a larger study, to investigate whether suppression or other effects of blastogenesis, as observed in rodents, could be shown in the lymphocytes of a population occupationally exposed to low levels of benzene.

\section{Material and methods}

Blood samples were obtained from subjects representing different age groups within a refinery population. Sixty six men with low average exposure to benzene and 33 control men were investigated. The 66 men worked in jobs where benzene or material containing benzene was handled and all had been potentially exposed to benzene for periods in excess of five years. Three main groups were identified, shipping, oil movements, and aromatics production. Exposures were assessed from previous personal and workplace air samples taken on individuals in similar jobs collected over a period of years. The data are classified in table 1, according to shift average (time weighted average (TWA)) and level (time unspecified). Some of the jobs-for example, loading and unloading of benzene on the jetty-have strict requirements for the wearing of protective breathing apparatus. In other areas the wearing of respiratory protection varies. The controls were selected from the refinery population based on evidence of presumed non-exposure to known genotoxic agents. A detailed questionnaire on health status and social habits was completed by each individual. This study was part of a larger study and the blood samples were collected at weekly intervals in batches of eight over 13 weeks. Sufficient serum and other agents, acquired in single batches, were purchased initially to enable all tests to be performed with identical material. Table 2 shows the numbers of individuals categorised by age, tobacco smoking, and alcohol consumption. In addition, individuals were categorised as to whether they had been exposed to

Table 1 Classification of exposure of operators and maintenance personnel in three working areas

\begin{tabular}{|c|c|c|c|c|c|c|c|c|c|c|}
\hline \multirow[b]{2}{*}{ Activity } & \multirow[b]{2}{*}{ Process } & \multirow[b]{2}{*}{ Job type } & \multirow[b]{2}{*}{ No in job } & \multicolumn{2}{|c|}{$\begin{array}{l}\text { Exposure TWA } \\
\text { long term (ppm) }\end{array}$} & \multicolumn{2}{|c|}{$\begin{array}{l}\text { Exposure } T W A \\
\text { sometime (ppm) }\end{array}$} & \multicolumn{2}{|c|}{$\begin{array}{l}\text { Level sometime } \\
\text { (ppm) }\end{array}$} & \multirow[t]{2}{*}{ Material } \\
\hline & & & & $1-5$ & $<1$ & $5-10$ & $1-5$ & $>100$ & $10-100$ & \\
\hline Stanlow & $\begin{array}{l}\text { Shipping } \\
\text { Oil movements } \\
\text { Shipping oil movements } \\
\text { Aromatics } \\
\text { Aromatics }\end{array}$ & $\begin{array}{l}\text { Operators } \\
\text { Operators } \\
\text { Maintenance } \\
\text { Operators } \\
\text { Maintenance }\end{array}$ & $\begin{array}{l}16 \\
50 \\
25 \\
28 \\
40\end{array}$ & $\begin{array}{l}2 \\
3\end{array}$ & $\begin{array}{l}14 \\
50 \\
22 \\
28 \\
36\end{array}$ & $\begin{array}{l}16 \\
25 \\
40\end{array}$ & $\begin{array}{l}50 \\
28\end{array}$ & $\begin{array}{l}16 \\
25 \\
28 \\
40\end{array}$ & 50 & \begin{tabular}{l} 
Pygas Mogas \\
Mogas \\
Mogas \\
Benzene \\
Benzene \\
\multicolumn{1}{c}{ stream }
\end{tabular} \\
\hline
\end{tabular}

Exposure represented by breathing zone concentrations averaged over a full shift. Level represented by breathing zone concentrations lasting for any time during a shift. Pygas = approx $30 \%$ benzene; mogas = approx $1-5 \%$ benzene; benzene stream $=30-100 \%$ benzene. 
Table 2 Individuals categorised by age, exposure and smoking and drinking habits

\begin{tabular}{|c|c|c|c|c|c|c|c|c|c|c|c|c|c|c|c|c|c|c|}
\hline \multirow[b]{3}{*}{$\begin{array}{l}\text { Drinking } \\
\text { Smoking }\end{array}$} & \multicolumn{18}{|c|}{ Age interval (years) } \\
\hline & \multicolumn{3}{|c|}{$20-24$} & \multicolumn{3}{|c|}{$25-34$} & \multicolumn{2}{|c|}{$35-44$} & \multicolumn{3}{|c|}{$45-54$} & \multicolumn{3}{|c|}{$55-60$} & \multicolumn{3}{|c|}{ All } & \multirow[b]{2}{*}{++} \\
\hline & - & + & ++ & - & + & ++ & - & + & ++ & - & + & ++ & - & + & ++ & - & + & \\
\hline $\begin{array}{l}\text { Non } \\
\text { Ex } \\
\text { Current }\end{array}$ & $\begin{array}{l}1 \\
0 \\
0\end{array}$ & $\begin{array}{l}0 \\
0 \\
0\end{array}$ & $\begin{array}{l}0 \\
0 \\
0\end{array}$ & $\begin{array}{l}0 \\
0 \\
2\end{array}$ & $\begin{array}{l}2 \\
0 \\
0\end{array}$ & $\begin{array}{l}0 \\
1 \\
4\end{array}$ & $\begin{array}{c}\text { Expos } \\
1 \\
2 \\
0 \\
\text { Contr }\end{array}$ & $\begin{array}{l}d \\
5 \\
7 \\
6 \\
l\end{array}$ & $\begin{array}{l}1 \\
5 \\
4\end{array}$ & $\begin{array}{l}1 \\
0 \\
3\end{array}$ & $\begin{array}{l}2 \\
2 \\
5\end{array}$ & $\begin{array}{l}0 \\
4 \\
2\end{array}$ & $\begin{array}{l}1 \\
1 \\
1\end{array}$ & $\begin{array}{l}0 \\
1 \\
1\end{array}$ & $\begin{array}{l}0 \\
0 \\
1\end{array}$ & $\begin{array}{l}4 \\
3 \\
6\end{array}$ & $\begin{array}{r}9 \\
10 \\
12\end{array}$ & $\begin{array}{r}1 \\
10 \\
11\end{array}$ \\
\hline $\begin{array}{l}\text { Non } \\
\text { Ex } \\
\text { Current }\end{array}$ & $\begin{array}{l}1 \\
0 \\
0\end{array}$ & $\begin{array}{l}1 \\
1 \\
0\end{array}$ & $\begin{array}{l}0 \\
0 \\
0\end{array}$ & $\begin{array}{l}0 \\
0 \\
0\end{array}$ & $\begin{array}{l}5 \\
4 \\
1\end{array}$ & $\begin{array}{l}0 \\
0 \\
4\end{array}$ & $\begin{array}{l}1 \\
0 \\
0\end{array}$ & $\begin{array}{l}0 \\
2 \\
0\end{array}$ & $\begin{array}{l}1 \\
2 \\
0\end{array}$ & $\begin{array}{l}0 \\
0 \\
1\end{array}$ & $\begin{array}{l}1 \\
1 \\
3\end{array}$ & $\begin{array}{l}0 \\
0 \\
2\end{array}$ & $\begin{array}{l}0 \\
0 \\
1\end{array}$ & $\begin{array}{l}0 \\
1 \\
0\end{array}$ & $\begin{array}{l}0 \\
0 \\
0\end{array}$ & $\begin{array}{l}2 \\
0 \\
2\end{array}$ & $\begin{array}{l}7 \\
9 \\
4\end{array}$ & $\begin{array}{l}1 \\
2 \\
6\end{array}$ \\
\hline $\begin{array}{l}\text { Non } \\
\text { Ex } \\
\text { Current }\end{array}$ & $\begin{array}{l}2 \\
0 \\
0\end{array}$ & $\begin{array}{l}1 \\
1 \\
0\end{array}$ & $\begin{array}{l}0 \\
0 \\
0\end{array}$ & $\begin{array}{l}0 \\
0 \\
2\end{array}$ & $\begin{array}{l}7 \\
4 \\
1\end{array}$ & $\begin{array}{l}0 \\
1 \\
8\end{array}$ & $\begin{array}{l}2 \\
2 \\
0\end{array}$ & $\begin{array}{l}5 \\
9 \\
6\end{array}$ & $\begin{array}{l}2 \\
7 \\
4\end{array}$ & $\begin{array}{l}1 \\
0 \\
4\end{array}$ & $\begin{array}{l}3 \\
3 \\
8\end{array}$ & $\begin{array}{l}0 \\
4 \\
4\end{array}$ & $\begin{array}{l}1 \\
1 \\
2\end{array}$ & $\begin{array}{l}0 \\
2 \\
1\end{array}$ & $\begin{array}{l}0 \\
0 \\
1\end{array}$ & $\begin{array}{l}6 \\
3 \\
8\end{array}$ & $\begin{array}{l}16 \\
19 \\
16\end{array}$ & $\begin{array}{r}2 \\
12 \\
17\end{array}$ \\
\hline
\end{tabular}

Non-smoker: never smoked more than occasionally. Ex-smoker: stopped three or more months ago. Current smoker: one or more cigarettes, cigars, or pipes a day; $-:$ non-drinker, + : social drinker, $++:$ regular drinker (cf $0,1,2$ respectively-fig 5 ).

diagnostic ionising radiation during the previous 12 months.

\section{SAMPLE COLECTION AND PREPARATION OF LYMPHOCYTES}

Sixty millilitres of blood were collected by venepuncture during early morning. Haematology smears were prepared immediately. Blood for cell counts was placed in $1 \mathrm{ml}$ sequestrene tubes. The balance was placed in ethylenediaminetetra-acetic acid (EDTA) universal bottles for processing. This was done by adding equal volumes of phosphate buffered saline (PBS(A)) to each of the universal bottles to dilute the blood and, after mixing the contents of each bottle, this was layered on to a lymphocyte separation solution (Lymphoprep-Nyegaard Norway) in a 50 $\mathrm{ml}$ centrifuge tube. This was then centrifuged at $800 \mathrm{G}$ for 20 minutes. The resulting mononuclear cell layers from the three tubes were then transferred to a single fresh $50 \mathrm{ml}$ centrifuge tube when $25 \mathrm{ml}$ of PBS(A) was added and mixed thoroughly with a Pasteur pipette and centrifuged again at $250 \mathrm{G}$ for 10 minutes.

A portion of the lymphocyte suspension from each blood sample was adjusted to $1.3 \times 10^{6} \mathrm{WBC} / \mathrm{ml}$ in Eagle's minimal essential medium (EMEM) 15. Seventy five millilitres of this suspension was distributed into each of $24 \mathrm{u}$-wells of a microtitre plate. Sets of three microcultures were dosed with $10,5,1 \cdot 0$, $0 \cdot 5,0 \cdot 25$, and $0 \cdot 1 \mu \mathrm{g} / \mathrm{ml} \mathrm{PHAP}$ and vehicle, added in 25 microlitre volumes. These microcultures were then incubated at $37 \pm 0.5^{\circ} \mathrm{C}$ in humidified $5 \pm 0.1 \% \mathrm{CO}_{2}$ in air for $\mathbf{4 6}$ to $\mathbf{4 8}$ hours and then $\left(\mathrm{H}^{3}\right)$ thymidine was added to each to give $1 \mu \mathrm{Ci} / \mathrm{ml}$. The microcultures were reincubated for 18 hours and then harvested on to glass fibre paper $(\mathrm{GF} / \mathrm{C})$ filter discs using an Ilacon disc cutter harvester. The dried discs were tritium counted in 2,5-diphenyloxazole (PPO)/toluene scintillation mixture, quench correction being made by the external standard method.

\section{STATISTICAL ANALYSIS}

Maximum response values to PHA stimulation were analysed in relation to smoking, drinking, and $x$ ray exposure in the exposed and control groups by one way analysis of variance and step wise multiple linear regression. Data were not available for seven individuals owing to technical artefact and they were excluded from the analysis.

\section{Results}

Dose response curves (decays per minute (DPM) against $6 \log$ PHA doses) were drawn for each individual and figs 1 and 2 show examples. Those

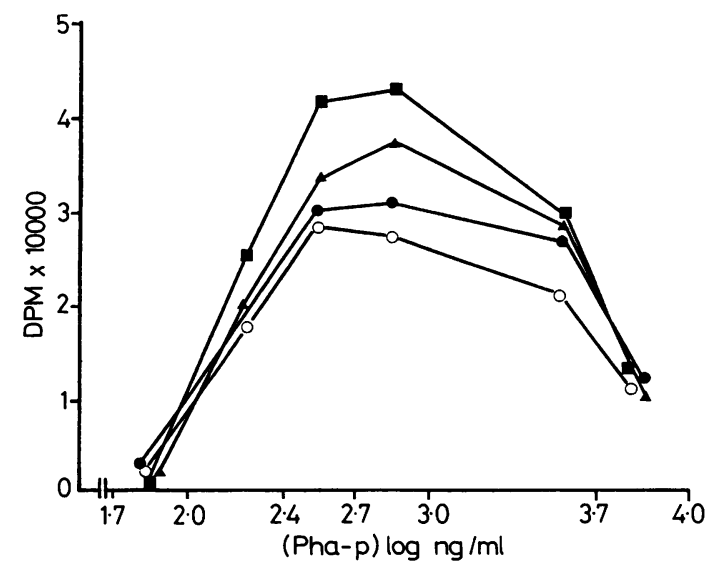

Fig 1 Response to mitogenic stimulation in four individuals. Symbols represent different individuals. 


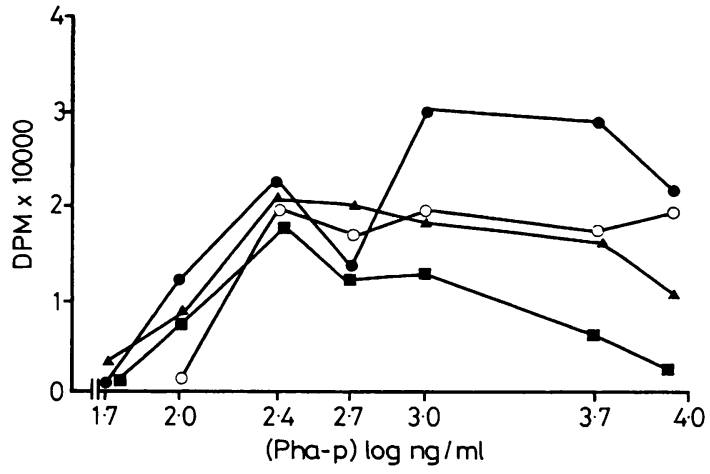

Fig 2 Response to mitogenic stimulation in four individuals. Symbols represent different individuals.

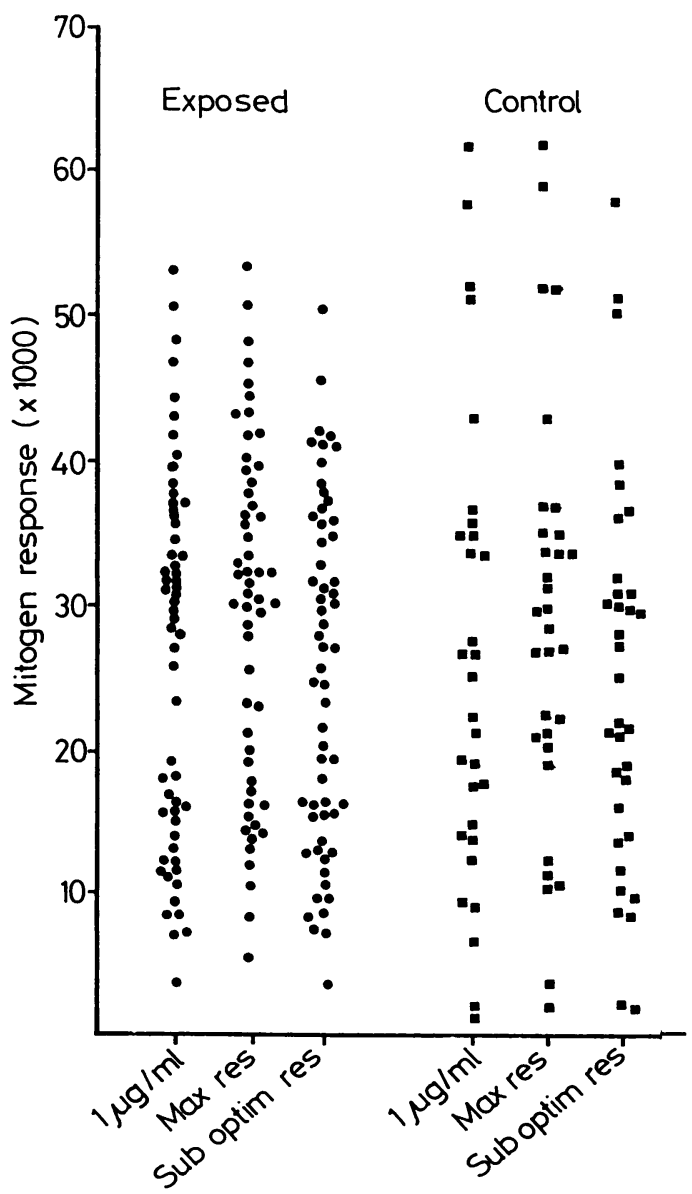

Fig 3 Mitogenic response (DPM) in control and exposed individuals. Maximum response, suboptimal response, and response at $1 \mu \mathrm{g} / \mathrm{ml}$ of $P H A$.

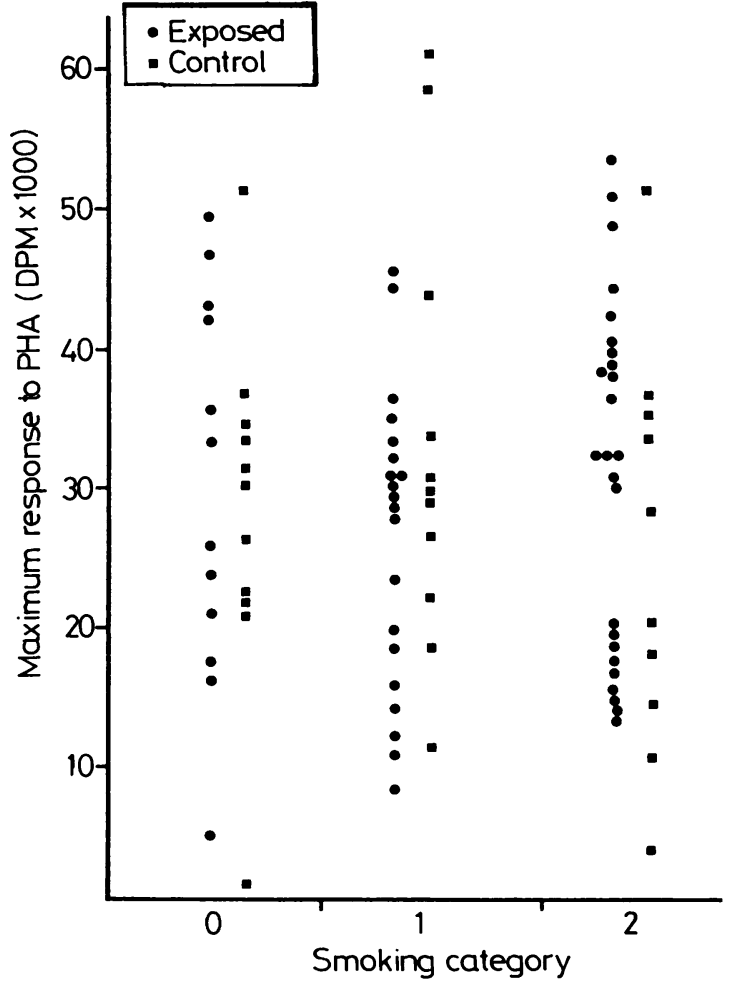

Fig 4 Maximum response and smoking habits. Smoking categories: $0=$ non-smoker, $I=$ ex smoker, $2=$ current smoker.

individuals who had relatively low maximal mitogenic response were included in the analysis. These were believed to be genuine low or non-responders, as distinct from technical artefacts, although the latter could not be excluded as a possible explanation for the low responses. The maximal, suboptimal, and responses at $1 \mu \mathrm{g} / \mathrm{ml}$ of PHA were determined for each sample and the values for the exposed and control groups were plotted and are shown in fig 3. As may be seen there was no statistical difference in the maximum response between the exposed (mean $28928 \pm 1524$ $\mathrm{SE}$ ) and the control (mean $28304 \pm 2483 \mathrm{SE}$ ) groups, although there is a suggestion of a bimodal response in the exposed group at $1 \mu \mathrm{g} / \mathrm{ml}$. The exposed and control groups were then categorised into various smoking, drinking, and $x$ ray categories. There was no difference in these various categories, either in the control or exposed group (figs 4-6), which was confirmed by statistical analysis (table 3 ). When the maximum PHA response was plotted against the age of the individuals there was a negative correlation both in the exposed and control group as may be seen from fig 7 . The effect, 


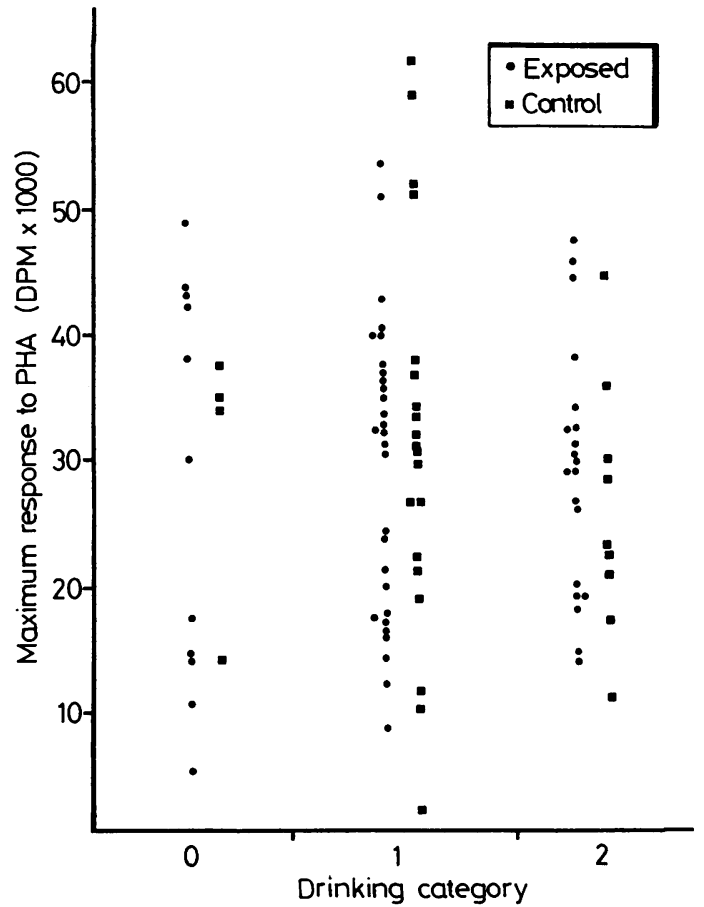

Fig 5 Maximum response and drinking habits. Drinking categories: $0=$ less than 2 units, $1=2-20$ units, $2=$ more than 20 units (one unit $=284 \mathrm{ml}$ beer, $24 \mathrm{ml}$ spirits, $114 \mathrm{ml}$ wine, $57 \mathrm{ml}$ fortified wine).

however, only accounts for $5 \%$ of the variability on multivariate regression analysis. The maximum PHA response seemed to be reduced by 310 DPM a year.

\section{Discussion}

Considering the comparatively low potential exposure of the individuals in the exposed group as compared with the control group it is not surprising that no difference was detected using this technique. The effect of age was consistent with the findings of Campbell $e t$ $a l$ in their work with lymphocytes after exposure to

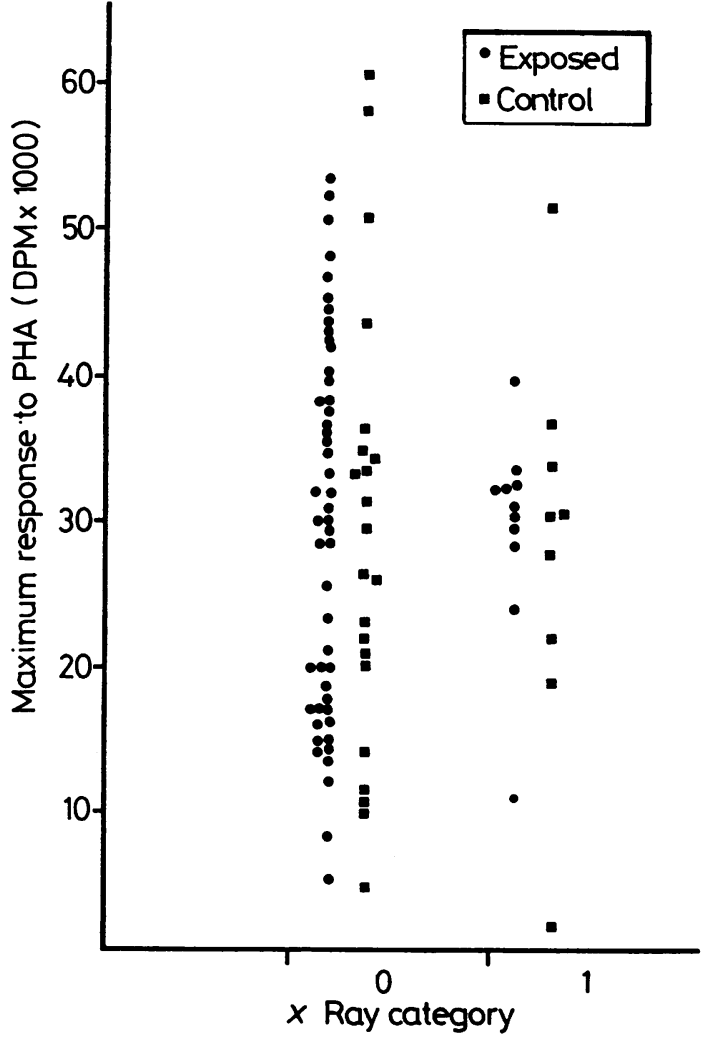

Fig 6 Maximum response and exposure to $x$ rays.

Diagnostic $x$ ray categories: $0=$ no exposure, $1=$ exposure.

asbesto ${ }^{16}$ and has been well described by Kishimoto $e t$ al who showed that the response to PHA stimulation in human lymphocytes declined with age. ${ }^{17}$ Silverman et al noted that the PHA response in his groups was in fact increased in smokers under the age of 40 but failed to show an effect over the age of 40 , implying that the effect then is either less pronounced or more variable. ${ }^{18}$ We could not show such an effect in our smoking groups. The suggestion of a bimodal response in the

Table 3 Maximal mitogenic response (decays a minute), exposed and control, in various groups

\begin{tabular}{|c|c|c|c|c|c|c|c|c|}
\hline & \multicolumn{3}{|c|}{ Smoking } & \multicolumn{3}{|c|}{ Drinking } & \multicolumn{2}{|l|}{$x$ Ray } \\
\hline & Non & $E x$ & Current & Non & Social & Regular & Non & Exposed \\
\hline \multirow{4}{*}{$\begin{array}{l}\text { No } \\
\text { X } \\
\text { SE }\end{array}$} & & & & \multicolumn{2}{|c|}{ Control } & & & \\
\hline & 11 & 10 & 12 & & 20 & 9 & 20 & \\
\hline & 28290 & 32067 & 25172 & 29621 & 29377 & 25334 & 26938 & 30405 \\
\hline & & & 4090 & \multicolumn{2}{|c|}{ Exposed } & 3117 & 3051 & 3992 \\
\hline No & 12 & 20 & 27 & 11 & 30 & 18 & 42 & 17 \\
\hline $\begin{array}{l}\mathbf{X} \\
\mathbf{S F}\end{array}$ & 29125 & 25584 & 31317 & 27962 & 28685 & 28246 & 28194 & 26938 \\
\hline SE & 3576 & 2155 & 2303 & 4522 & 2329 & 2081 & 1996 & 3051 \\
\hline
\end{tabular}

$\mathbf{X}=$ Mean decays a minute.

$\mathbf{S E}=$ Standard error . 


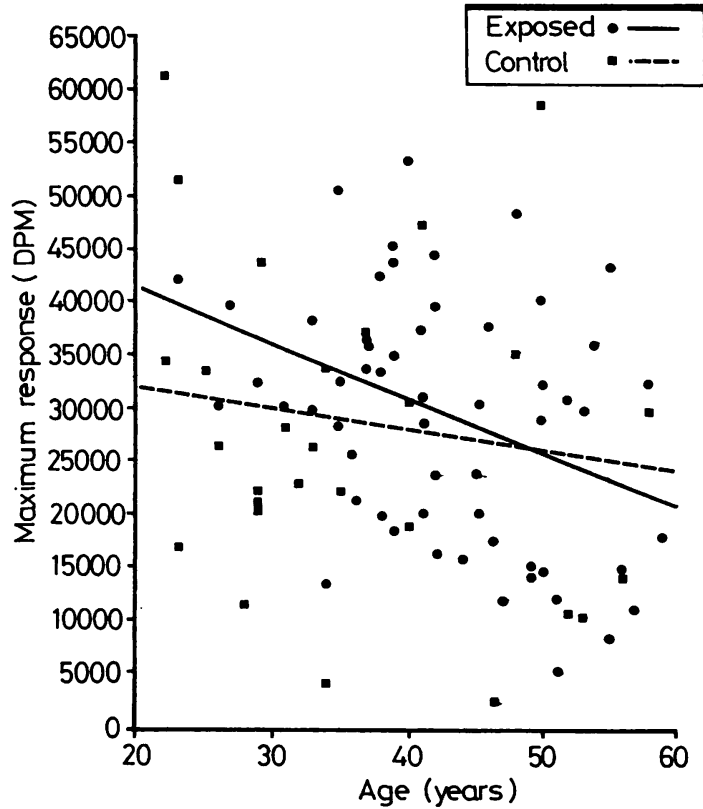

Fig 7 Maximum response and age (years). $E=$ Exposed, $C=$ control.

exposed group at $1 \mu \mathrm{g} / \mathrm{ml}$ of PHA is interesting and might represent a differential stimulation of lymphocyte subpopulations or types rather than technical artefact. This observation possibly warrants further investigation.

Wolff and Bodycote suggest that incorporation of tritiated thymidine during PHA stimulation may not reflect accurately the cell proliferation rate after the first round of replication. ${ }^{19}{ }^{20}$ In a cell conditioned medium there is transformation of tritiated thymidine to unincorporable compounds. In the present study, however, tritiated thymidine was added fresh to the medium in the last 18 hours of culture, which would only permit one cycle of replication.

Irons et al have shown that the effect of benzene metabolites such as parabenzoquinone and hydroquinone is sulphydryl-group (SH) dependent and may be protected against by adding low molecular weight SH compounds-for example, 2-mercapto-ethanol or dithiothreitol. ${ }^{13}$ Furthermore, similar experiments using SH compounds indicate that suppression of blastogenesis involves internal cellular SH groups critical for lymphocyte blastogenesis. They state that the most likely explanation of these findings involves the SH alkylating properties of compounds such as parabenzoquinone. Previous studies have shown benzene exposure in vivo to be associated with a block of arrest of already proliferating bone marrow cells. ${ }^{121}$ This cell cycle arrest together with the apparent SH cell activity of parabenzoquinone and hydroquinone has led Irons et al to examine tubulin as a potential macromolecular target for their compounds. ${ }^{13}$ In their recent review of quinones as toxic metabolites of benzene they referred to microtubule integrity as a known factor to be required not only for spindle formation and division but also for regulation of surface receptor movement and normal signal transduction of the cell surface. Consequently, they have concluded that the possible mode of action of some of the metabolites of benzene is by interfering with the microtubule function and also microtubule dependent processes such as blastogenesis, secretion, and cell division.

The cytoskeleton has been implicated as being an important structure for early events associated with promotion. ${ }^{12}$ The effects of low level benzene metabolites in lectin stimulated lymphocytes resemble those induced by established promoters such as 12-0tetradecanoyl phorbol 13 acetate, ${ }^{223}$ raising the possibility that these compounds may alter lymphocyte differentiation through similar mechanisms. A correlation between the ability of phorbol esters to act as comitogens to PHA stimulated lymphocyte cultures and their tumour promoting ability has previously been demonstrated. ${ }^{22}$ Thus comitogenic enhancement of lymphocyte growth response by benzene metabolites may explain the seemingly anomalous hypoplastic responses observed in bone marrow of animals and man after exposure to benzene, and suggest that these agents be of primary importance with regard to the disruption of growth control on differentiating bone marrow cell populations. Although possibly not the only mechanism operating in benzene leukaemogenesis, the evidence for promotional activity, using these methods, is worth investigating further in established carcinogenic studies.

This study was unable to show any effect in the exposed individuals as compared with the controls with respect to microtubule dependent processes. This may be either because there are different processes operating in man and rodents or because the target dose of benzene metabolites in the exposed group was insufficient to cause such effects. There is no doubt that the exposures of this particular group of employees are extremely low compared with the exposure values of the past that are known to cause health effects in man.

We thank the employees who took part in the study and Dr A C MacLean for his early support, Mr Bloomberg and Mr I Smith for preparing the blood samples, Dr M K Molyneux for the occupational hygiene data, and Dr R C Dewdney and Dr D P Lovell for help in processing and analysing the samples and for statistical analysis of the data, respectively. 
Requests for reprints to: Dr A Yardley-Jones, BIBRA, Woodmansterne Road, Carshalton, Surrey SM5 4DS.

\section{References}

1 International Agency for Research on Cancer. Monograph on the evaluation of carcinogenic risk of chemicals to humans $1892 ; 4$ (suppl):56-7.

2 Maltoni C, Conti B, Cotti G. Benzene: a multipotential carcinogen. Results of long-term bioassays performed at the Bologna Institute of Oncology. Am J Ind Med 1983;4:589-630.

3 Laskin S, Goldstein BD, eds. Benzene toxicity: a critical review. $J$ Toxicol Environ Health suppl 1977:2:1-148.

4 Decoufle P, Blattner W, Blair A. Mortality among chemical workers exposed to benzene and other agents. Environ Res 1983;30:16-25.

5 White MC, Infante PF, Chu KC. A quantitative estimate of leukaemia mortality associated with occupational exposure to benzene. Risk Analysis 1982;2:195-204.

6 Maltoni $C$. Myths and facts in the history of benzene carcinogenicity. In: Mehlman MA, ed. Advances in modern environmental toxicology: carcinogenicity and toxicity of benzene. Vol 4. Princeton: Princeton Scientific Publishers Inc, 1983:1-15.

7 Tunek A, Plat KL, Pryzybylski M, Oesch F. Multistep metabolic activation of benzene. Effect of superoxide dismutase on covalent binding to microsomal macromolecules, and identification of glutathione conjugates using high pressure liquid chromatography and field desorption mass spectrometry. Chem Biol Interact 1980;33:1-17.

8 Irons RD, Neptun DA. Effects of the principal hydroxymetabolites of benzene on microtubule polymerization. Arch Toxicol 1980;45:297-305.

9 Irons RD, Dent JG, Baker TS, Rickert DE. Benzene is metabolized and convalently bound in bone marrow in situ. Chem Biol Interact 1980;30:241-5.

10 Sawahata T, Rickert DE, Greenlee WF. Metabolism of benzene and its metabolites in bone marrow. In: Irons RD, ed. Toxicology of the blood and bone marrow. New York: Raven Press, 1985:141-8.
11 Irons RD, Neptun DA, Pfeifer RW. Inhibition of lymphocyte transformation and microtubule assembly by quinone metabolites of benzene: evidence for a common mechanism. Journal of the Reticuloendothelial Society 1981;30:359-72.

12 Pfeifer RW, Irons RD. Effect of benzene metabolites on PHAstimulated lymphopoiesis in rat bone marrow. Journal of the Reticuloendothelial Society 1982;31:155-70.

13 Irons RD. Quinones as toxic metabolites of benzene. $J$ Toxicol Environ Health 1985:16:673-8.

14 Morimoto K, Wolff S. Increase in sister chromatid exchanges and perturbations of cell division kinetics in human lymphocytes by benzene metabolites. Cancer Res 1980;40:1189-93.

15 Pfeifer RW, Irons RD. Alteration of lymphocyte function by quinones through sulfhydryl-dependent disruption of microtubule assembly. Int J Immunopharmacol 1983:5:463-70.

16 Campbell MJ, Wagner MMF, Scott MP, Brown DG. Sequential immunological studies in an asbestos-exposed population. Clin Exp Immunol 1980;39:176-82.

17 Kishimoto S, Tomino S. Inomata K, et al. Age-related changes in the subsets and functions of human T lymphocytes. $J$ Immunol 1978;121:1773-80.

18 Silverman NA, Potvin C, Alexander JC Jr, Chretien PB. In vitro lymphocyte reactivity and T-cell levels in chronic cigarette smokers. Clin Exp Immunol 1975;22:285-90.

19 Wolff S, Bodycote J. Transformation of tritiated thymidine in culture medium to unincorporable compounds by human lymphocytes and CHO cells. Environ Mutagen 1985:7(suppl 3):91.

20 Bodycote J, Wolff S. Metabolic breakdown of $\left[{ }^{3} \mathrm{H}\right]$ thymidine inability to measure human lymphocyte proliferation by incorporation of radioactivity. Proc Natl Acad Sci $\backslash S .4$ 1986;83:4749-53.

21 Irons RD, Pfeifer RW, Aune TM, Pierce CW. Soluble immune response suppressor inhibits microtubule function in vivo and microtubule assembly in vitro. $J$ Immunol 1984:133:2032-6.

22 Kensler TW, Mueller GC. Retinoic acid inhibition of the comitogenic action of mezerein and phorbol esters in bovine lymphocytes. Cancer Res 1978;38:771-5.

23 Touraine JL, Hadden JW, Touraine F. Hadden EM. Estensen R. Good RA. Phorbol myristate acetate: a mitogen selective for a T-lymphocyte subpopulation. J Exp Med 1977:145:460-5. 